\title{
Effects of S/B Remedy Containing Scutellaria baicalensis and Bupleurum scorzonerifolfium on Hepatic Interleukin-6 Related Signal Transducer and Activator of Transcription 3 Activation in Mice through Cell-Cell Interaction
}

\author{
Chang-Yin Lee, ${ }^{a}$ Jir-You Wang, ${ }^{a, b}$ Tzu-Chun Chen, ${ }^{a}$ Jeng-Kae JiAng, ${ }^{c}$ Chi-Hao Peng, ${ }^{a}$ \\ Cheng-Deng Kuo, ${ }^{d}$ Wen-Chi Chang, ${ }^{e}$ Jen-Hwey Chiv, ${ }^{*, a f f, g}$ and Chew-Wun Wu ${ }^{f}$ \\ ${ }^{a}$ Institute of Traditional Medicine, School of Medicine, National Yang-Ming University; ${ }^{e}$ Laboratory Animal Center, \\ National Yang-Ming University; Taipei 112, Taiwan, ROC.: ${ }^{b}$ Department of Orthopedic, Taipei Veterans General Hospital; \\ ${ }^{c}$ Division of Colorectal Surgery, Department of Surgery, Taipei Veterans General Hospital; ${ }^{d}$ Department of Medical \\ Research and Education, Taipei Veterans General Hospital; ${ }^{f}$ Division of General Surgery, Department of Surgery, Taipei \\ Veterans General Hospital; Taiwan 112, ROC.: and ${ }^{g}$ Department of Surgery, Cheng-Hsiun Hospital; Taipei, Taiwan 112, \\ ROC. Received January 2, 2011; accepted January 25, 2011; published online February 9, 2011
}

Signal transducer and activator of transcription 3 (STAT3) plays an important role in regulating interleukin 6 (IL-6) related growth control of the liver. Our previous study demonstrated that a mixture containing Scutellaria baicalensis and Bupleurum scorzonerifolfium (S/B remedy) modulated the growth of hepatocytes during liver regeneration after $2 / 3$ partial hepatectomy. The aim of this study was to investigate whether $S / B$ remedy induced mouse hepatic STAT3 activation directly in hepatocytes or indirectly via non-parenchymal cell-hepatocyte interaction. Direct S/B remedy effects were studied using primarily isolated hepatocytes; while C57BL/6J mice were used to study indirect effects of S/B remedy using gadolinium chloride to deplete Kupffer cells' function. The results showed that $\mathrm{S} / \mathrm{B}$ remedy and its active constituents did not directly activate growth-related signaling in primarily isolated hepatocytes. However, S/B remedy induced STAT3 and subsequently suppressor of cytokine signaling (SOCS3) activation in mouse liver and increased serum IL-6 level in a dose-dependent manner, which could be partially blocked by pretreatment with gadolinium chloride. Oligonucloetide microarray analysis from $\mathrm{S} / \mathrm{B}$ remedy-treated peripheral blood leukocytes demonstrated an up-regulation of IL-6 gene expression. We conclude that $\mathrm{S} / \mathrm{B}$ remedy did not directly induce STAT3 activation in vitro, but induced hepatic IL-6 related STAT3 activation through non-parenchymal cell-hepatocyte interaction in vivo. The results provide important information on the molecular mechanisms of $\mathrm{S} / \mathrm{B}$ remedy for treatment of human liver diseases.

Key words signal transducer; medicinal herb; liver regeneration; Scutellaria baicalensis

It is well known that cytokines such as tumor necrosis factor- $\alpha$ (TNF- $\alpha$ ) and interleukin 6 (IL-6), secreted from nonparenchymal cells, are major factors in priming quiescent hepatocytes to proliferative status during liver regeneration. ${ }^{1,2)}$ Signal transducer and activator of transcription-3 (STAT3) is a component of the transcription factor family that mediates IL-6-related growth responses. ${ }^{3,4)}$ There is evidence that the cyclin D1 gene is an important target of STAT3 in hepatocytes, and that STAT3 acts as a negative regulator of cyclin D1 transcription during fetal liver development. Whereas STAT3 positively regulates cyclin D1 expression in $\mathrm{HCC}$ cells at the initiation of liver regeneration. ${ }^{5,6)}$ Nevertheless, information concerning how medicinal herbs affect an IL-6STAT3 signaling pathway remains to be elucidated.

The liver is an organ containing many cell types that perform different biological functions. Some liver functions are mainly achieved by one cell type, while other functions require aids from more than one cell type. For example, transforming growth factor $\beta$ (TGF- $\beta$ ) secreted from activated Kupffer cells and hepatic stellate cells exerts potent fibrogenic effects via both autocrine and paracrine patterns in liver fibrosis. ${ }^{7-9)}$ During liver regeneration, lipopolysaccharide-induced TNF- $\alpha$ and IL-6 secreted from Kupffer cells play important roles in priming the hepatocytes, activating STAT3 signaling pathway, and finally stimulating growth of parenchymal cells or hepatocytes. ${ }^{1,2)}$ Such non-parenchymal cell-hepatocyte interaction oftentimes cannot be elucidated by using a single cell system, such as Kupffer cell or hepato- cyte alone cultures.

Historically, herbs are used to treat many kinds of liver disease in Asia, especially in Chinese populations. Since the 1990 s the prevalence and costs of alternative medicine worldwide have been increasing. ${ }^{10,11)}$ Herbal medicine or supplement use is becoming popular among patients with liver diseases. ${ }^{12)}$ However, exact cellular mechanisms on how medicinal herbs work are yet to be understood. Previously, our laboratory demonstrated that a remedy containing Scutellaria baicalensis and Bupleurum scorzonerifolfium (S/B remedy) stimulated hepatic cell growth during liver regeneration. ${ }^{13)}$ Nevertheless, how $\mathrm{S} / \mathrm{B}$ remedy modulates hepatic growth-related signaling pathways remains unclear. Therefore, the aim of this study was to test the hypothesis that S/B remedy induced hepatic STAT3 activation in mice through non-parenchymal cell-hepatocyte interaction.

\section{MATERIALS AND METHODS}

Animals/Cell Cultures C57BL/6J, 6 to 8 weeks old, weighting 20 to $25 \mathrm{~g}$, were purchased from the animal center of the National Science Council, Taiwan, R.O.C. They were fed with standard diet and water ad libitum and treated under the regulations of the "Guide for the Care and Use of Laboratory Animals" (National Academy Press; 1996). The studies were approved by the ethics committee for animal study of National Yang-Ming University, Taipei, Taiwan, R.O.C. Gadolinium chloride III $\left(\mathrm{GdCl}_{3}\right.$, Sigma-Aldrich Co., St. 
Louis, Missouri, U.S.A.) was used for depleting the in vivo Kupffer cells' function. ${ }^{14)}$ Primary mouse hepatocytes were cultured in DMEM (Dulbecco's modified Eagle's medium, GibcoBRL, 12800-017) at $37^{\circ} \mathrm{C}, 5 \% \mathrm{CO}_{2}$, supplemented with $10 \%$ fetal calf serum, $2 \mathrm{mmol}$ L-glutamine, non-essential amino acid (GibcoBRL, 11140-050, Grand Island, NY, U.S.A.), $100 \mathrm{IU} / \mathrm{ml}$ penicillin, $100 \mu \mathrm{g} / \mathrm{ml}$ streptomycin and $1.5 \mu \mathrm{g} / \mathrm{ml}$ fungizone (GibcoBRL, 15290-018).

Herb Preparation and Liquid Chromatography S/B remedy containing Scutellaria baicalensis $(\mathrm{Sb})$ and Bupleurum scorzonerifolfium (Bs) and its compositions ( $\mathrm{Sb}$ and $\mathrm{Bs}$ ) was prepared as described previously. ${ }^{13,15)}$ They were obtained from a G.M.P. company (KODA Pharmaceutical Co., Taiwan), and quality control standardization was done. Four pure compounds purified and characterized from Sb, namely, baicalin (molecular weight (MW) 446.37), baicalein (MW 270.20), chrysin (MW 254.24), and wogonin (MW 284.27) were purchased from Nacalai Tesque (Kyoto, Japan). They were quantified with high performance liquid chromatography (HPLC). The system consisted of a chromatographic pump (PM-80, Bioanalytical System, West Lafayette, IN, U.S.A.), an injector (Rheodyne 7125, Cotati, CA, U.S.A.) equipped with a $20 \mu \mathrm{l}$ sample loop, and an ultraviolet detector (Varian, Walnut Creek, CA, U.S.A.). Herbal extract and its major ingredients were separated using an Alltima reversed phase C18 column $(250 \times 4.6 \mathrm{~mm}$ i.d.; particle size $5 \mu \mathrm{m}$; Deerfield, IL, U.S.A.) preserved at an ambient temperature to perform the ideal chromatographic phase. The mobile phase was comprised of $10 \mathrm{mmol}$ monosodium phosphoric acid-acetonitrile $(69: 31, \mathrm{v} / \mathrm{v}, \mathrm{pH} 3.0)$, with a flow rate $1.0 \mathrm{ml} / \mathrm{min}$. The mobile phase was filtered through a Millipore $0.45 \mu \mathrm{m}$ filter and degassed prior to use. The UV wavelengths were set at $203 \mathrm{~nm}$ and $280 \mathrm{~nm}$ for the determination of Bupleuri radix and Scutellaria baicalensis, respectively. Output data from the detector were integrated via an EZChrom chromatographic data system (Scientific Software, San Ramon, CA, U.S.A.). Several steps for quality experiments including retention time, spiking of authentic standard, change of wavelength and change of the composition of mobile phase were used to examine the contents in S/B remedy. The percentage of pure compounds in S/B remedy such as baicalin, baicalein, wogonin, chrysin were $150.1 \mathrm{mg} / \mathrm{g}$, $14.3 \mathrm{mg} / \mathrm{g}, 3.3 \mathrm{mg} / \mathrm{g}, 1.0 \mathrm{mg} / \mathrm{g}$, respectively.

Isolation of Mice Hepatocytes for Primary Culture Isolation of hepatocytes from C57BL/6J strain was used to study direct pharmacological effects on mice hepatocytes and was prepared as described previously. ${ }^{15)}$ Isolated hepatocytes $\left(1 \times 10^{4}\right)$ were cultured on collagen type I-coated plates (Orange Scientific, Belgium) for $4 \mathrm{~h}$, followed by serum-free culture for another $24 \mathrm{~h}$, then drug treatment was performed. The purity of isolated hepatocytes was analyzed by flow cytometry with forward-scatter and side-scatter determination. The STAT3 activation in primarily cultured hepatocytes with/without pretreatment of SB remedy or its constituents, $\mathrm{Sb}$ and $\mathrm{Bs}$, was analyzed by Western blot.

In Vivo Effects of S/B Remedy on Mouse Liver Since $\mathrm{S} / \mathrm{B}$ remedy was extracted with water, it was dissolved in $\mathrm{H}_{2} \mathrm{O}$ before use. After treatment with different dosages $(0,1$, $50 \mathrm{mg} / \mathrm{kg}$ ) of S/B remedy via intraperitoneal injection due to uncertainty of bio-availability through oral route, animals were sacrificed under adequate anesthesia $(40 \mathrm{mg} / \mathrm{kg})$ (Zoletil
50, Virbac Lab., Carros, France) at various time intervals $(0 \mathrm{~min}, 4,24,48 \mathrm{~h})$ and the livers were removed and stored until use.

Antibodies and Western Blot Analysis For protein analysis, the cell pellets from primarily cultured hepatocytes and herbs-treated liver tissues were homogenized and protein concentration measured by Bradford's method. ${ }^{16)}$ A total of $60 \mu \mathrm{g}$ of homogenate was separated on a $10 \%$ sodium dodecyl sulfate (SDS)-polyacrylamide gel electrophoresis, transferred to a polyvinylidene difluoride (PVDF) membrane, blocked with $2 \%(\mathrm{w} / \mathrm{v})$ bovine serum albumin, washed with TBS buffer $(0.1 \%$ Twin $20,100 \mathrm{mmol} \mathrm{NaCl}, 10 \mathrm{mmol}$ Tris$\mathrm{Cl}, \mathrm{pH}$ 7.5), followed by incubation at $4{ }^{\circ} \mathrm{C}$ for overnight with specific antibodies against $1: 500$ diluted total/phosphorylated forms of STAT3 (Tyr705) (Cell Signaling Technology, Inc., MA, U.S.A.), $1: 1000$ diluted Cyclin D1 (Cell Signaling Technology, Inc., MA, U.S.A.) and 1:300 diluted SOCS3 (ab16030, Abcam, plc, U.K.). Antibodies such as $\beta$ actin $(1: 2000)$, total/phosphorylated forms of extracellular signal-regulated kinase (ERK) $(1: 250)$, total/phosphorylated forms of p38 mitogen activated protein kinase (MAPK) (Thr180/Tyr182) $(1: 250)$ and total/phosphorylated forms of c-Jun N-terminal kinase (JNK) (Thr183) were commercially available (AbFrontier Co., Ltd., Seoul, Korea). Anti-rabbit immunoglobulin G (IgG) horse-radish peroxidase (HRP)linked Antibody (Cell Signaling Technology, Inc., MA, U.S.A.) in $1: 1000$ dilution was used as a secondary antibody. For the immune blotted membranes, enhanced chemiluminescence (ECL, Amersham Pharmacia Biotech., Inc., NJ, U.S.A.) detection was used, and they were analyzed by autoradiography. The optical density (OD) values were obtained from a computer equipped with image analysis software (PhotoCapt, Vilber Lourmat, Marne LuVallee Cedex, France). Since STAT3 and SOCS3 were sequentially expressed during liver regeneration, liver tissue extract from liver remnants after partial hepatectomy was used as positive control (PC).

Total RNA Extraction and Real-Time Quantitative Reverse Transcription-Polymerase Chain Reaction (RTPCR) Total RNA from liver tissues $(0.1 \mathrm{~g})$ was isolated using the RNeasy kit (Qiagen Inc., CA, U.S.A.). For removing residual amounts of genomic DNA remaining, RNasefree DNase (Qiagen Inc.) digestion for $15 \mathrm{~min}$ at room temperature was performed twice using a RW1 buffer wash after each digestion. RNA was quantified by spectrophotometry at $260 \mathrm{~nm}$. Complementary DNA synthesis and polymerase chain reaction were carried out using TaqMan One-Step RTPCR Master Mix Reagents (Applied Biosystems, CA, U.S.A.) with $T a q$ Man probes-primers set (Applied Biosystems) on ABI PRISM 7000 Sequence Detection System (Applied Biosystems). Since inhibitory $\kappa \mathrm{B}(\mathrm{I} \kappa \mathrm{B})$ kinase/nuclear factor- $\kappa \mathrm{B}(\mathrm{NF}-\kappa \mathrm{B})(\mathrm{IKK} / \mathrm{NF}-\kappa \mathrm{B})$ and c-myc signaling play critical roles in a variety of physiological processes in liver regeneration, their gene expressions were analyzed and quantified by RT-PCR. The sequences of primers such as C-myc (myc-3) primer: sense, 5'-CCATCCTATGTTGCGG-3', antisense, 3'-AGGGGTCAATGCACTC-5'; IKK primer, sense: 5'-TGCCGTCCTCGCTAAC-3', antisense: 5'-GCCTTATCAGCGTCAGT-3'; beta-2 microglobulin (B2M), sense, 5' AATGGGAAGCCGAACA-3', and anti-sense, 5'-CAGTAGACGGTCTTGGG-3' were used. The relative expression of 
IKK and c-myc mRNA was normalized to the amount of $\mathrm{B} 2 \mathrm{M}$ in the same RNA extract by using the standard curve method described by the manufacturer. All samples were triplicated.

Measurement of Serum IL-6 Level Serum IL-6 level was determined by using commercially available RayBio\&reg mouse cytokine antibody array (RayBiotech, Norcross, GA, U.S.A.) and enzyme-linked immunosorbent assay (ELISA) kit (BioSource International, CA, U.S.A.).

Isolation of RNA from Peripheral Blood Leukocytes and Oligonucleotide Microarray Analysis The RNA from mouse peripheral blood leukocytes (PBLs) was isolated with Qiagen RNeasy mini kit in accordance with the manufacturer's instruction (Qiagen, 79254, Tezas, U.S.A.). ${ }^{17)}$ The concentration of total RNA required for oligonucleotide microarray analysis should be at least $0.6 \mu \mathrm{g} / \mathrm{ml}$ and the quality $260 / 280$ and $260 / 230 \geqq 1.8$. The RNA samples were sent to National Yang-Ming University VYM genome research center for mouse affymetrix expression set 4302.0 microarray analysis (Affymetrix, Seattle, U.S.A.). The outcomes were analyzed after normalizing to the global signal and the relative expression level of each gene was analyzed by Genespring software. ${ }^{18)}$

Statistics Results were expressed as the mean \pm S.E.M. Differences were analyzed by one way analysis of variance (ANOVA) followed by Dunnett posthoc test. A $p$ value of $<0.05$ was considered statistically significant (GraphPad Prism 4, GraphPad Inc., San Diego, CA, U.S.A.).

\section{RESULTS}

Effects of S/B Remedy on Hepatocyte Growth in Mice Receiving 2/3 Partial Hepatectomy (PH) Our previous works in mice demonstrated that $\mathrm{S} / \mathrm{B}$ stimulated hepatocyte growth in regenerating liver after $2 / 3$ partial hepatectomy. However, due to $\mathrm{PH}$ being a strong stimulus for activation of the hepatic STAT3 signaling pathway, it would mask the effect of S/B remedy on IL6-related STAT3 activation in the liver remnant of PH-mice (Fig. 1). Therefore, the pharmacological effect of $\mathrm{S} / \mathrm{B}$ remedy was elucidated in non-PH mice.

Effect of S/B Remedy and Its Constituents on STAT3 Activation in Primarily Cultured Hepatocytes To investigate direct herbal effects on STAT3 activation in mice hepatocytes, $\mathrm{S} / \mathrm{B}$ remedy and its constituents ( $\mathrm{Sb}$ and $\mathrm{Bs}$ ) were added into primarily cultured hepatocytes for different time intervals $(0,3,6 \mathrm{~h})$. Then the cells were collected, homogenized, blotted, and probed with antibodies against tyrosine (Tyr705), phosphorylated STAT3, and STAT3 protein. The results showed that there was minimal STAT3 activation in cultured hepatocytes treated with low dose $(3 \mathrm{mg} / \mathrm{ml}) \mathrm{Sb}$ or $\mathrm{S} / \mathrm{B}$ remedy. More convincingly, no such activation at $6 \mathrm{~h}-$ treatment with higher doses $(10,30 \mathrm{mg} / \mathrm{ml})$ of $\mathrm{S} / \mathrm{B}$ remedy or its constituents ( $\mathrm{Sb}$ and $\mathrm{Bs}$ ) was observed (Fig. 2A). Furthermore, compared to the control group $(0 \mathrm{mg} / \mathrm{ml}), \mathrm{Sb}$ alone and Bs alone suppressed STAT3 phosphorylation in $3 \mathrm{~h}$ - and $6 \mathrm{~h}$ herbs-treated hepatocytes (Fig. 2B).

Effects of Sb and Its Active Pure Compounds on ERK, JNK and p38 Activation in Primarily Cultured Hepatocytes To investigate direct herbal effects on growth-related molecular signaling in mice hepatocytes, S/B remedy and its constituents ( $\mathrm{Sb}$ and $\mathrm{Bs}$ ) were administered to cultured hepa-

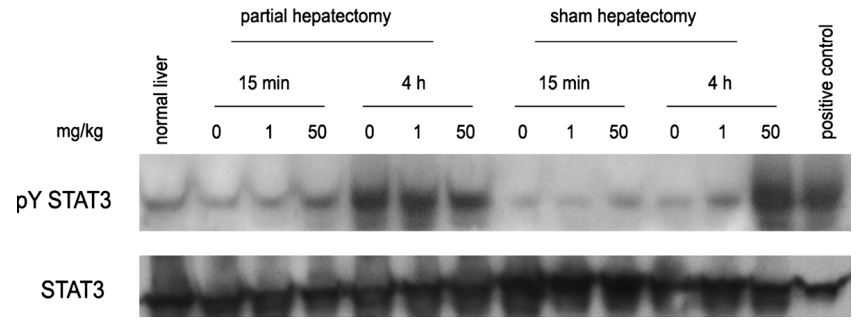

Fig. 1. Effects of S/B Remedy on Sham- and Partial Hepatectomized Liver in Mice

After sham- and $2 / 3$ partial hepatectomy, mouse liver tissues at the different time points $(0,15 \mathrm{~min}, 4 \mathrm{~h})$ after S/B remedy $(0,1,50 \mathrm{mg} / \mathrm{kg})$ treatment were homogenized blotted, and probed with antibodies against tyrosine (Tyr705) phosphorylated STAT3 and STAT3 protein. Since pY STAT3 was highly expressed during liver regeneration, liver tissue extract from liver remnants after partial hepatectomy was used as positive control (PC)

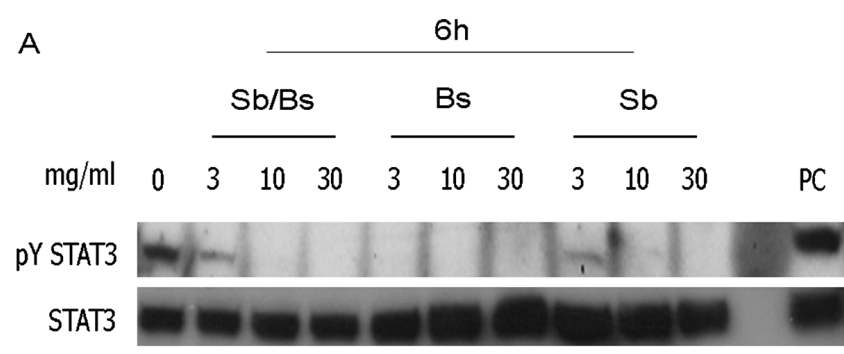

B

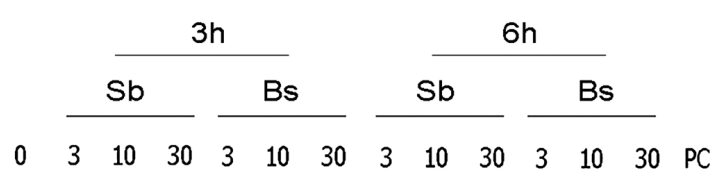

pY STAT3

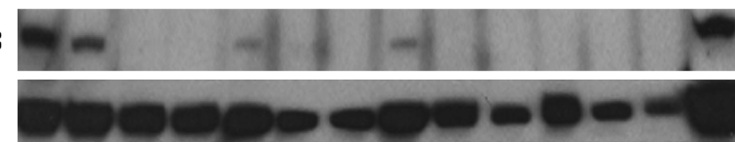

Fig. 2. Effects of S/B Remedy and Its Constituents on STAT3 Activation in Primarily Cultured Hepatocytes

After primary hepatocytes $\left(1 \times 10^{4}\right)$ were isolated and cultured in serum free medium for $24 \mathrm{~h}, \mathrm{~S} / \mathrm{B}$ remedy and its constituents ( $\mathrm{Sb}$ and $\mathrm{Bs}$ ) were added into primarily cultured hepatocytes for different time intervals $(3,6 \mathrm{~h})$. Then the cells were collected, homogenized, blotted, and probed with antibodies against tyrosine (Tyr705) phosphorylated STAT3 and STAT3 protein. The results showed that there were minimal STAT3 activation in cultured hepatocytes treated with low dose $(3 \mathrm{mg} / \mathrm{ml})$ but not higher doses $(10,30 \mathrm{mg} / \mathrm{ml})$ of $\mathrm{Sb}$ and $\mathrm{S} / \mathrm{B}$ remedy treatment for $6 \mathrm{~h}(\mathrm{~A})$. Compared to the control group $(0 \mathrm{mg} / \mathrm{ml}), \mathrm{Sb}$ alone and Bs alone induced few STAT3 phosphorylation in $3 \mathrm{~h}$ and 6 h-herbs-treated hepatocytes (B). Since pY STAT3 was highly expressed during liver regeneration, liver tissue extract from liver remnants after partial hepatectomy was used as positive control (PC)

tocytes. Sb was chosen to be used for further in vitro studies due to lower cytotoxicity compared to Bs extract. After Sb and its active compounds (baicalin, baicalein, wogonin, chrysin) were added into primarily cultured hepatocytes for $10 \mathrm{~min}$, the cells were collected, homogenized, blotted, and probed with antibodies against phospho-form and total-form ERK, JNK and p38 proteins. The results showed that $\mathrm{Sb}$ did not induce significant activation of ERK, p38 and JNK signaling in cultured hepatocytes (Fig. 3A). Actually, high dose of $\mathrm{Sb}(30 \mathrm{mg} / \mathrm{ml})$ suppressed the activation of these 3 proteins. Interestingly, four pure compounds (baicalin, baicalein, wogonin, chrysin) at the concentration of $10^{-5} \mathrm{~mol}$ and the mixture of all these compounds did not induce JNK, ERK and p38 activation (Fig. 3B). These data suggest that neither $\mathrm{S} / \mathrm{B}$ remedy nor its constituents directly activate the growth- 
A

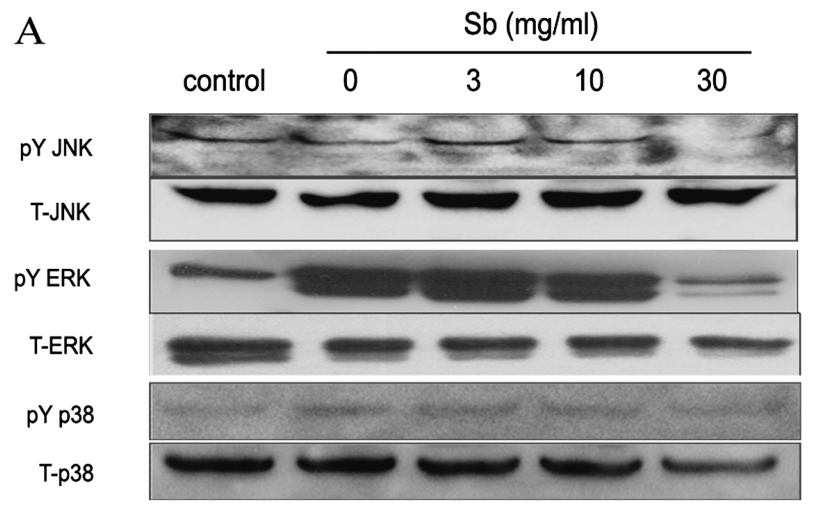

B

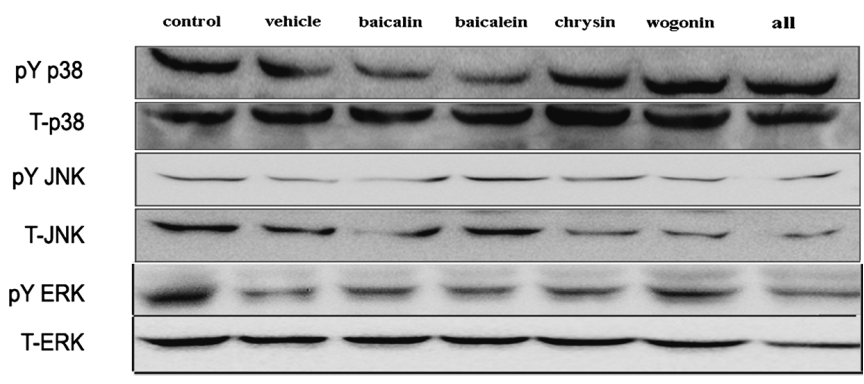

Fig. 3. Effects of $\mathrm{Sb}$ and Its Activate Pure Compounds on ERK, JNK and p38 Activation in Primarily Cultured Hepatocytes

After primary hepatocytes $\left(1 \times 10^{4}\right)$ were isolated and cultured in serum free medium for $24 \mathrm{~h}, \mathrm{Sb}(\mathrm{A})$ and its active compounds (baicalin, baicalein, wogonin, chrysin) were added into primarily cultured hepatocytes for $10 \mathrm{~min}$, the cells were collected, homogenized, blotted, and probed with antibodies against phospho-form and total-form of ERK, JNK and $\mathrm{p} 38$ proteins. The effects of 4 pure compounds $\left(10^{-5} \mathrm{~mol}\right)$ and the mixture of these compounds were also analyzed (B).

related signaling in primarily cultured hepatocytes.

Kinetic Change of STAT3 Tyrosine Phosphorylation in S/B Remedy-Treated Liver To study the kinetics of hepatic STAT3 activation, mouse liver tissue samples from livers extracted at different time points $(0,15 \mathrm{~min}, 4 \mathrm{~h})$ after S/B remedy $(0,1,50 \mathrm{mg} / \mathrm{kg})$ treatment, were homogenized, blotted, and probed with antibodies against tyrosine phosphorylated STAT3 and STAT3 protein. The results showed that S/B remedy induced hepatic STAT3 activation in a time- and dose-dependent manner (Fig. 4A). The quantification of phosphorylated STAT3/STAT3 and Cyclin D1/ $\beta$-actin in S/B remedy-treated livers was shown in Fig. 4B.

IL-6 from Kupffer Cells and Peripheral Blood Leukocytes (PBLs) Played Important Roles in S/B RemedyTreated Hepatic STAT3 Activation To test the hypothesis that S/B remedy induced hepatic STAT3 activation through the release of IL-6 from Kupffer's cells, gadolinium chloride $(10 \mathrm{mg} / \mathrm{kg})$ was pretreated $24 \mathrm{~h}$ before S/B remedy treatment, followed by determination of hepatic STAT3 phosphorylation at different time points $(0,15 \mathrm{~min}, 4 \mathrm{~h})$ by immunoblotting. The results showed S/B remedy-induced STAT3 phosphorylation could be partially blocked by gadolinium chloride treatment (Figs. 5A, B). Analysis by cytokine array (Fig. 5C) and enzyme-linked immunosorbent assay (ELISA) (Fig. 5D) of IL-6 levels in S/B remedy-treated serum showed that an increase of IL-6 had a parallel change with hepatic STAT3 phosphorylation. Since the amount of IL-6 in S/B remedytreated serum could not be completely blocked by pretreatment with gadolinium chloride, IL-6 secreted from another
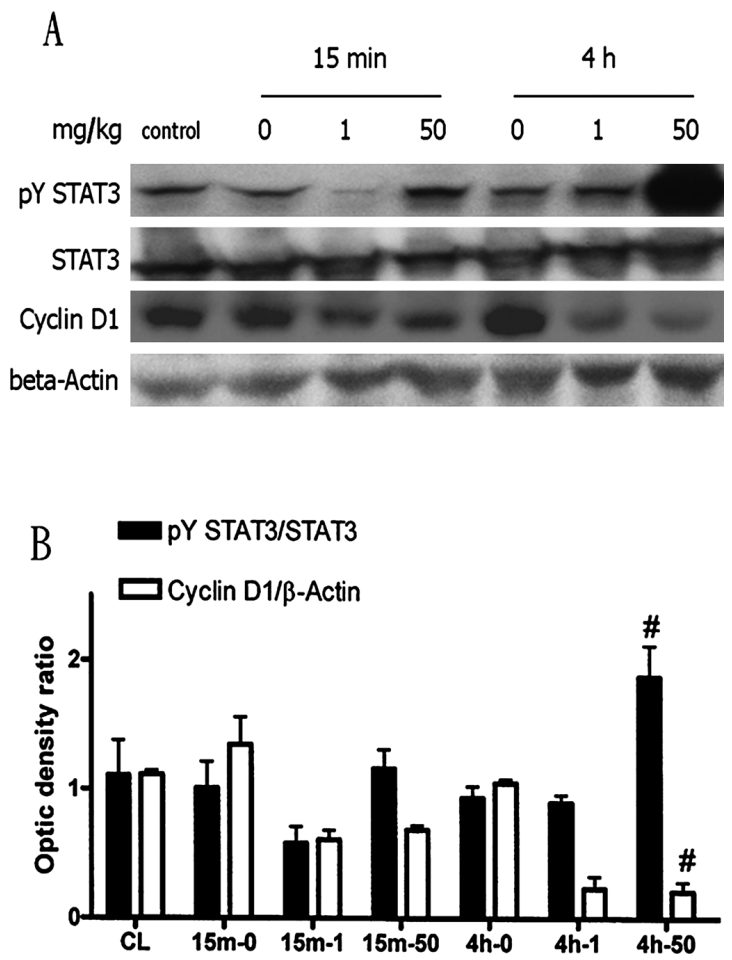

Fig. 4. Kinetic Change of STAT3 Tyrosine Phosphorylation in S/B Remedy-Treated Liver

Mouse liver tissues at the different time points $(0,15 \mathrm{~min}, 4 \mathrm{~h})$ after $\mathrm{S} / \mathrm{B}$ remedy $(0$, $1,50 \mathrm{mg} / \mathrm{kg}$ ) treatment, were homogenized, blotted, and probed with antibodies against tyrosine (Tyr705) phosphorylated STAT3 and STAT3 protein (A). Phosphorylated STAT3/STAT3 and Cyclin D1/ $\beta$-actin in S/B remedy-treated livers was quantified (B). \# indicates statistical significance $(p<0.05)$ compared to $4 \mathrm{~h}-0$ group.

cell type after herbal treatment was postulated. Due to the fact that peripheral blood leukocytes (PBLs) were the first line of drug-cell interaction when S/B remedy was absorbed into blood stream, microarray analysis on PBLs was performed and the results disclosed an up-regulated IL-6 gene expression $4 \mathrm{~h}$ after S/B remedy treatment (Fig. 5E). These data suggested that IL-6 secreted from Kupffer cells and possibly peripheral PBLs played important roles in S/B remedytreated IL-6-related STAT3 activation.

S/B Remedy Up-Regulated Hepatic IKK and c-myc Gene Expression Since I $\kappa$ B kinase/NF- $\kappa$ B (IKK/NF- $\kappa$ B) and c-myc signaling play critical roles in a variety of physiological processes in the regulation of hepatocyte cell growth, the expression of immediate early genes such as IKK and cmyc (myc-3) were quantitatively analyzed by real-time PCR in S/B remedy-treated liver. The results showed that hepatic IKK and c-myc gene expression were up-regulated by S/B remedy treatment in a dose-dependent manner, which could be blocked by pretreatment of gadolinium chloride. (Figs. $6 \mathrm{~A}, \mathrm{~B})$

SOCS3 Played an Important Role in Termination of STAT3 Activation in S/B Remedy-Treated Liver To investigate the role of SOCS3, a negative regulator for STAT3 activation, in S/B remedy-treated liver, SOCS3 proteins were analyzed with Western blot on liver homogenates after S/B remedy treatment for $48 \mathrm{~h}$. The results demonstrated that there was increased SOCS3 expression and a reciprocally decreased STAT3 activation in the $48 \mathrm{~h}$ herb-treated livers. (Fig. 7). 
A

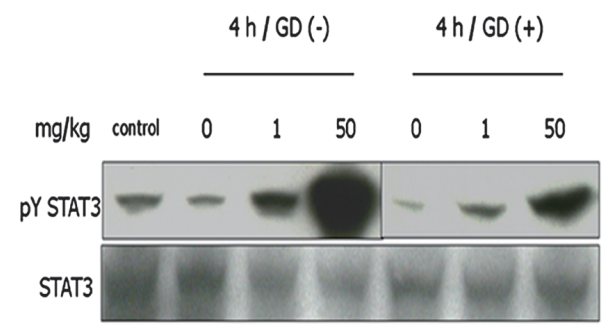

B

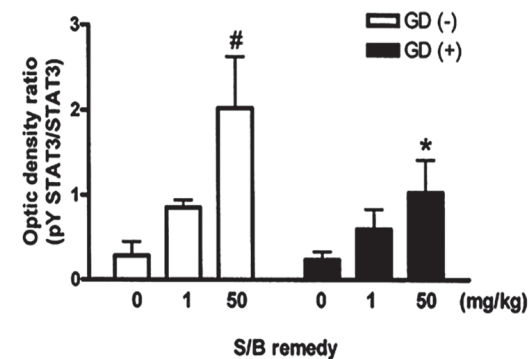

C

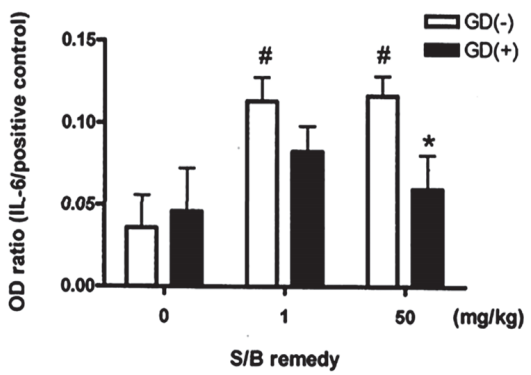

D

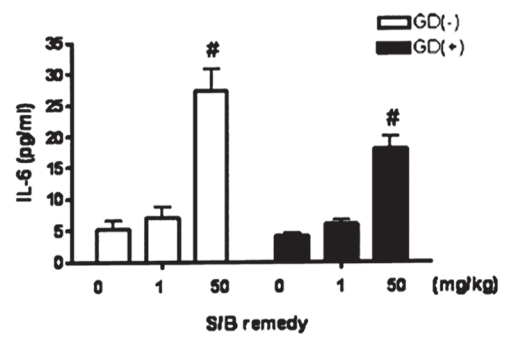

E
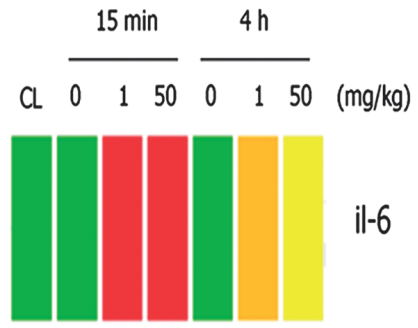

il-6

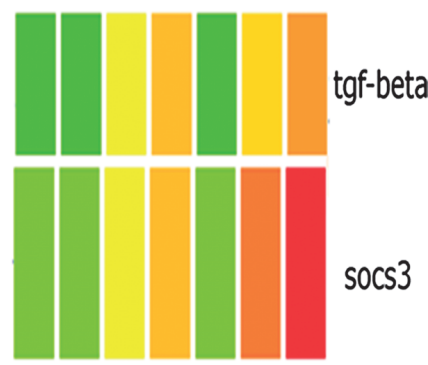

Fig. 5. Effects of Gadolinium Chloride on S/B Remedy-Induced Hepatic STAT3 Activation and Serum IL-6 Level

Gadolinium chloride $(10 \mathrm{mg} / \mathrm{kg})$ was pretreated $24 \mathrm{~h}$ before S/B remedy treatment, followed by determination of hepatic STAT3 phosphorylation at different time points $(0$, $15 \mathrm{~min}, 4 \mathrm{~h}$ ) by immunoblotting with antibodies against tyrosine phosphorylated STAT3 and STAT3 protein (A, B). IL-6 level in S/B remedy-treated serum was analyzed by cytokine array (C) and ELISA (D). IL-6 gene expression in peripheral blood leukocytes obtained from $4 \mathrm{~h}-\mathrm{S} / \mathrm{B}$ remedy-treated blood was analyzed by affymetric microarray analysis (E). \# indicates statistical significance $(p<0.05)$ compared to $0 \mathrm{mg} / \mathrm{kg}$ group. * indicates statistical significance $(p<0.05)$ compared to $50 \mathrm{mg} / \mathrm{kg}$ GD $(-)$ group.

\section{DISUCSSION}

There is consensus that IL-6 secreted from Kupffer cells plays an important role in activating the hepatic STAT3 signaling pathway during liver regeneration. ${ }^{19)}$ However, little is known concerning the modulatory effects of medicinal herbs on IL-6 related STAT3 signaling in the liver. To our knowledge, we are the first to elucidate the complexity of an herbal remedy on hepatic STAT3 activation through non-parenchymal cell-hepatocyte interaction, but not activation via direct drug-hepatocyte effects.

It is well known that many cell types such as Kupffer cells, endothelial cells, and hepatic stellate cells might participate in the secretion of IL- 6 during the process of liver regeneration. ${ }^{1,2)}$ Gadolinium chloride, a Kupffer cell function inhibitor, partially blocked S/B remedy-induced elevation of IL-6, and subsequently blocked hepatic STAT3 phosphoryla- tion. Two possibilities might contribute to such phenomenon; the dose of gadolinium chloride in this study was inadequate to completely deplete Kupffer cell function, or there are cells other than Kupffer cells participating in releasing IL-6 in S/B remedy-treated serum. A previous study has demonstrated that a gadolinium chloride dose of $10 \mathrm{mg} / \mathrm{kg}$ decreases $75 \%$ of the number of Kupffer cells and decreases more of their functions. ${ }^{20)}$ Another study shows that gadolinium chloride $(0.1 \mathrm{mmol} / \mathrm{kg}$, equivalent to $26 \mathrm{mg} / \mathrm{kg})$ attenuates thioacetamide-induced hepatotoxicity in rats by selectively inactivating Kupffer cells. ${ }^{21)}$ We used the lower dosage in our system, as the standard dose used for human MRI contrasting $(0.1 \mathrm{mmol} / \mathrm{kg})$ is too high for a mouse model. Due to the possibility of the involvement of peripheral leukocytes in production of serum IL- 6 by herbal treatment, the exact percentage of depletion in Kupffer cell function post treatment could not be determined in the present study. Nevertheless, the 
A

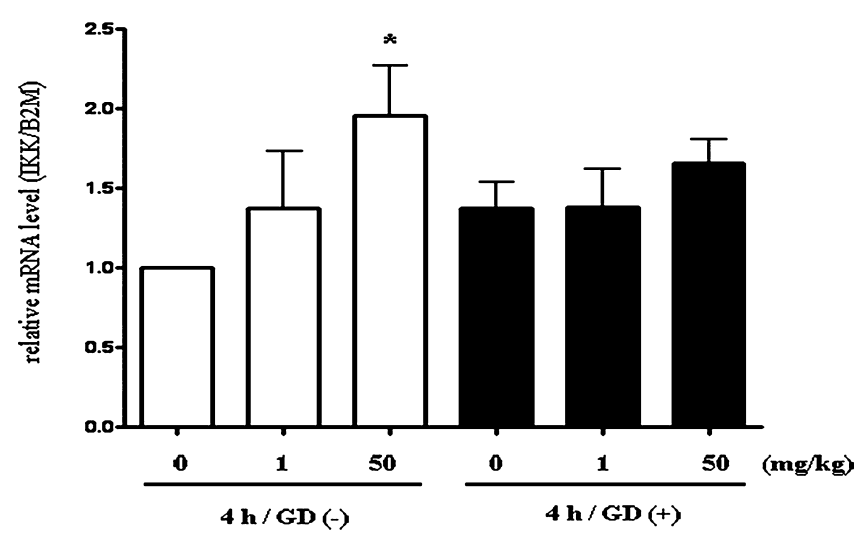

B

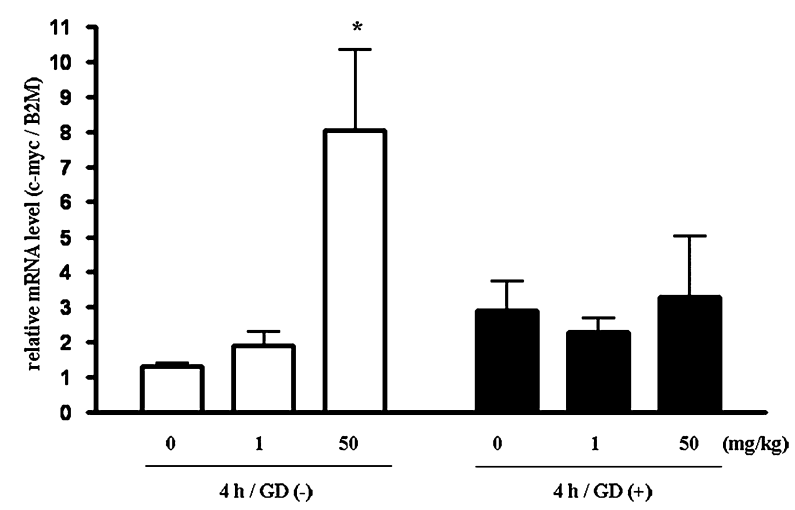

Fig. 6. Effects of S/B Remedy on I $\kappa$ B kinase (IKK) and c-myc Gene Expression in the Livers

Gadolinium chloride $(10 \mathrm{mg} / \mathrm{kg})$ was pretreated $24 \mathrm{~h}$ before S/B remedy treatment, followed by determination of hepatic IKK (A) and c-myc (myc-3, B) mRNA expression by real-time PCR. * indicates statistical significance $(p<0.05)$ compared to $0 \mathrm{mg} / \mathrm{kg}$ group.

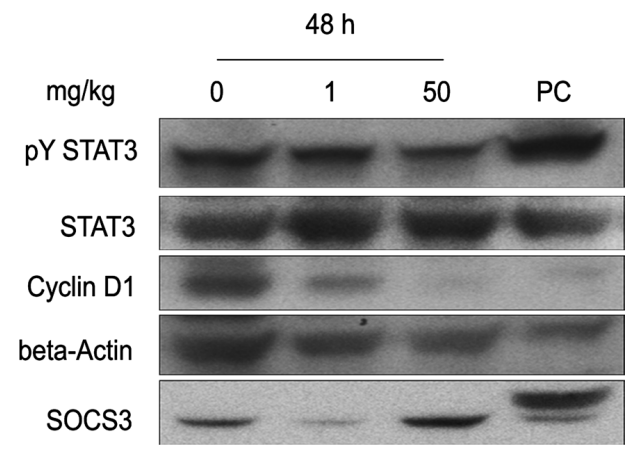

Fig. 7. Effects of S/B Remedy on Hepatic SOCS3 Expression

Mouse liver tissues at $48 \mathrm{~h}$ after $\mathrm{S} / \mathrm{B}$ remedy $(0,1,50 \mathrm{mg} / \mathrm{kg})$ treatment were homogenized, blotted, and probed with antibodies against SOCS3 protein. Beta-actin ( $\beta$-actin) was used as internal control. Since SOCS3 was expressed during liver regeneration, liver tissue extract from liver remnants after partial hepatectomy was used as positive control (PC).

amount of IL-6 in S/B remedy-treated serum was significantly higher than serum from mice only pretreated with gadolinium chloride, indicating the inhibitory effect of this compound on Kupffer cells function. In addition, the observation that IL-6 secreted from peripheral blood leukocytes (PBLs) is involved in S/B remedy induced hepatic STAT3 phosphorylation gets supported by oligonucleotide microar- ray analysis in this study. There are two reasons that IL-6 secreted by PBLs was not determined directly; 1) the amount of IL- 6 secreted from PBLs was beyond the detection limit due to the low yield of mouse PBLs population; 2) the gene expression from PBLs microarray analysis could actuarially reflex the PBLs response to an herbal remedy without encountering interpretation bias when IL-6 level was quantified in the medium of cultured white blood cells.

Accumulating evidence demonstrates that the therapeutic mechanisms of an herbal remedy cannot be dissected through a conventional pharmacological approach, that is to say, by using a single pure compound in a single system on a single target. ${ }^{22,23)}$ Nevertheless, it is necessary to provide evidence explaining the herbal effects of clinical observations. The results of our previous and present study taken together, demonstrate that Kupffer cells and PBLs are involved in modulating the growth of hepatocytes via different cytokines secreted during non-parenchymal cell-hepatocyte interaction. ${ }^{15)}$

It is true that the interaction between hepatocyte and Kupffer cell is not to the only way to activate STAT3. For example, tumor growth factor $\beta 1$ (TGF- $\beta 1$ ) released from activated Kupffer cells during liver fibrosis induces collagen synthesis gene expression in hepatic stellate cells, while TGF- $\beta 1$ simultaneously induces the apoptosis of hepatocytes. Previous studies have demonstrated that $\mathrm{Sb}$ extracts containing different amounts of baicalein and wogonin modulate cytokine productions such as TNF-alpha and IL (IL-12, IL-10) production in peripheral blood leukocytes and transforming growth factor $\beta 1$ (TGF- $\beta 1)$ in RAW 264.7 mouse macrophage cell line. ${ }^{24,25)}$ A large number of studies have shown the anti-inflammatory effect of $\mathrm{Sb}$ and its active compounds was through suppression of IL-6, NF- $\kappa$ B or AP-1 signaling pathways in many disease models. ${ }^{26-28)}$ However, under the situation of liver regeneration, cytokines such as tumor necrosis factor- $\alpha$ (TNF- $\alpha$ ) and IL-6 are the key factors in priming the hepatocytes and subsequently stimulating the growth of hepatocytes. ${ }^{1,2)}$ There is evidence that the activation of STAT3 plays an important role in mediating IL-6related growth responses during liver regeneration. ${ }^{3,4)}$ In the present study, since neither $\mathrm{Sb}$ alone, Bs alone, nor their active compounds activate a STAT3 signaling pathway in primarily cultured hepatocytes, the possibility of these compounds acting on Kupffer cells or PBLs is speculated. S/B remedy dose-dependently increases serum IL-6 level and hepatic STAT3 phosphorylation in vivo but not in primarily cultured hepatocytes, and Sb increases IL-6 gene expression in PBLs; these are facts that suggest IL-6-STAT3 signaling pathway as a target for S/B remedy through cell-cell interactions.

The suppressors of cytokine signaling (SOCS) are well known to modulate many cytokine-induced responses. ${ }^{28,29)}$ In a liver regeneration model, IL-6-induced STAT3 phosphorylation up-regulates SOCS3 gene expression, and in turn suppresses STAT3 phosphorylation in a negative feedback manner. ${ }^{30,31)}$ Recent studies have demonstrated the correlation between inhibition of tyrosine phosphorylation of the phosphatase SHP-2 in IL-6 signaling and the enhanced induction of SOCS3 messenger RNA. ${ }^{32}$ The fact that there is an increased SOCS3 expression with a reciprocally decreased STAT3 activation in this study supports the negative feed- 
back loop in cytokine induced STAT3 activation. Furthermore, the level of SOCS3 was down regulated at $1 \mathrm{mg} / \mathrm{kg}$, but up regulated at $50 \mathrm{mg} / \mathrm{kg}$ (Fig. 7). We attribute this phenomenon to interactions, either synergic or antagonizing effects, between compounds present in S/B remedy. Since herbal medicine has many active ingredients, it is reasonable to speculate that compound A induces SOCS3 expression at higher dose while no effect at lower dose; compound B suppresses SOCS3 expression at lower dose but not high dose. Accordingly, the above mentioned discrepancy can be explained by interactions between active compounds in the $\mathrm{S} / \mathrm{B}$ remedy.

Recently, a correlation was shown between persistently upregulated STAT3 phosphorylation and many malignancies, such as head and neck cancers, mammary carcinoma and hematological malignancies. ${ }^{33,34)}$ The cyclin D1 gene is an important target of STAT3 in hepatocytes, and STAT3 acts as a negative regulator of cyclin D1 transcription during fetal liver development. In contrast, STAT3 positively regulates cyclin D1 expression in HCC cells and at the initial phase of liver regeneration. ${ }^{5,6}$ Our results showed a reciprocal expression of hepatic STAT3 and cyclin D1, indicating that STAT3 in $\mathrm{S} / \mathrm{B}$ remedy treated hepatic cellular responses does not act as a positive regulator on cyclin D1 expression. In addition, the pharmacokinetics of S/B remedy does not up-regulate hepatic STAT3 phosphorylation in a persistent way, which makes the possibility that $\mathrm{S} / \mathrm{B}$ remedy increases hepatic STAT3 phosphorylation in such a way as to induce liver carcinogenesis unlikely.

In conclusion, herbal medicine is becoming a popular complementary medicine in the treatment of many diseases and in general maintenance of human health. However, the drug-drug, drug-cell, and cell-cell interactions are still beyond our comprehension. Our results provide important information for integrative treatment of human liver diseases and make the therapeutic effects of an herbal medicine more predictable.

Acknowledgements We declare that we have no conflicts of interest. This work was supported by Grants from Taipei Veterans General Hospital, Taiwan, ROC (VGH93349, V97E2-014, V98E2-012, NSC 92-2323-B-010-002) and Program for Promoting Academic Excellence of Universities Genome-Based Biomedical Research for the 21st Century (89-B-FA22-2-4) (YM95A-C-T04-17). We are indebt to National Yang-Ming University VYM genome research center for mouse affymetrix microarray analysis. We appreciate $\mathrm{Mr}$. Christof Arnold for his excellent manuscript editing.

\section{REFERENCES}

1) Fausto N., Campbell J. S., Riehle K. J., Hepatology, 43 (Suppl. 1), S45-S53 (2006)

2) Michalopoulos G. K., J. Cell Physiol., 213, 286-300 (2007).

3) Fausto N., "Liver Regeneration," 4th ed., Lippincott Williams \&
Wilkins, Philadelphia, PA, 2001.

4) Guschin D., Rogers N., Briscoe J., Witthuhn B., Watling D., Horn F., Pellegrini S., Yasukawa K., Heinrich P., Stark G. R., EMBO J., 14, 1421 - 1429 (1995).

5) Rossi G., Viola Magni M., Albi E., Arch. Biochem. Biophys., 464, 138-143 (2007).

6) Fu M., Wang C., Li Z., Sakamaki T., Pestell R. G., Endocrinology, 145, 5439-5447 (2004).

7) Friedman S. L., Liver Dis., 19, 129-140 (1999).

8) Thompson K. C., Trowern A., Fowell A., Marathe M., Haycock C., Arthur M. J., Sheron N., Hepatology, 28, 1518-1524 (1998).

9) Cheng K., Yang N., Mahato R. I., Mol. Pharm., 6, 772-779 (2009).

10) Eisenberg D. M., Cohen M. H., Hrbek A., Grayzel J., Van Rompay M. I., Cooper R. A., Ann. Int. Med., 137, 965-973 (2002).

11) Normile D., Science, 299, 188-190 (2003).

12) Ferrucci L. M., Bell B. P., Dhotre K. B., Manos M. M., Terrault N. A., Zaman A., Murphy R. C., Vanness G. R., Thomas A. R., Bialek S. R., Desai M. M., Sofair A. N., J. Clin. Gastroenterol., 44, e40-e45 (2010).

13) Wang J. Y., Chiu J. H., Tsai T. H., Tsou A. P., Hu C. P., Chi C. W., Yeh S. F., Lui W. Y., Wu C. W., Chou C. K., Int. J. Mol. Med., 16, 221231 (2005).

14) Jørgensen P. E., Gotzinger P., Scholz T., Gundersen Y., Sautner T., Függer R., Lilleaasen P., Aasen A. O., Shock, 16, 466- 472 (2001).

15) Wang J. Y., Chuang H. N., Chiu J. H., Fu S. L., Tsai T. H., Tsou A. P., Hu C. P., Chi C. W., Yeh S. F., Lui W. Y., Wu C. W., Chou C. K., Exp. Biol. Med., 231, 444-455 (2006).

16) Bradford M. M., Analy. Biochem., 72, 248-254 (1976).

17) Lederer J. A., Brownstein B. H., Lopez M. C., Macmillan S., Delisle A. J., Macconmara M. P., Choudhry M. A., Xiao W., Lekousi S., Cobb J. P., Baker H. V., Mannick J. A., Chaudry I. H., Physiol. Genomics, 32, 299-310 (2008).

18) Wang Z., Du Q., Wang F., Liu Z., Li B., Wang A. Wang Y., J. Neurochem., 88, 1406-1415 (2004).

19) Wuestefeld T., Klein C., Streetz K. L., Betz U., Lauber J., Buer J., Manns M. P., Müller W., Trautwein C., J. Biol. Chem., 278, 1128111288 (2003).

20) Kinoshita M., Uchida T., Nakashima H., Ono S., Seki S., Hiraide H., Shock, 23, 65-72 (2005).

21) Bautista M., Andres D., Cascales M., Morales-González J. A., Sánchez-Reus M. I., Int. J. Mol. Sci., 11, 4426-4440 (2010).

22) Chang C. J., Chiu J. H., Tseng L. M., Chang C. H., Chien T. M., Chen C. C., Wu C. W., Lui W. Y., Menopause, 13, 967-976 (2006).

23) Chiu J. H., Chen K. K., Chien T. M., Chiou W. F., Chen C. C., Wang J. Y., Lui W. Y., Wu C. W., Int. J. Impot. Res., 18, 335-342 (2006).

24) Blach-Olszewska Z., Jatczak B., Rak A., Lorenc M., Gulanowski B., Drobna A., Lamer-Zarawska E., J. Interferon Cytokine Res., 28, 571581 (2008)

25) Chuang H. N., Wang J. Y., Chiu J. H., Tsai T. H., Yeh S. F., Fu S. L., Lui W. Y., Wu C. W., Planta Med., 71, 440-445 (2005).

26) Fu J., Cao H., Wang N., Zheng X., Lu Y., Liu X., Yang D., Li B., Zheng J., Zhou H., Int. Immunopharmacol., 8, 1652-1657 (2008).

27) Li-Weber M., Cancer Treat. Rev., 35, 57-68 (2009).

28) Starr R., Hilton D. J., Bioessays, 21, 47-52 (1999)

29) Kovanen P. E., Leonard W. J., Curr. Biol., 9, R899-R902 (1999).

30) Dierssen U., Beraza N., Lutz H. H., Liedtke C., Ernst M., Wasmuth H. E., Trautwein C., J. Biol. Chem., 283, 9886-9895 (2008).

31) Campbell J. S., Prichard L., Schaper F., Schmitz J., Stephenson-Famy A., Rosenfeld M. E., et al., J. Clin. Invest., 107, 1285-1292 (2001).

32) Schmitz J., Weissenbach M., Heinrich P. C., J. Biol. Chem., 275 12848-12856 (2000).

33) Bromberg J. F., Horvath C. M., Besser D., Lathem W. W., Darnell J. E. Jr., Mol. Cell Biol., 18, 2553-2558 (1998).

34) Levy D. E., Lee C. K., J. Clin. Invest., 109, 1143-1148 (2002). 